\title{
Willingness to Vaccinate against COVID-19 among Healthcare Workers: An Online Survey in 10 Countries in the Eastern Mediterranean Region
}

\author{
Yasir Ahmed Mohammed Elhadi1 ${ }^{1,2}$, Azza Mehanna ${ }^{1}$, Yusuff Adebayo Adebisi ${ }^{3}$, Haider M. El Saeh ${ }^{4}$, \\ Saddam Abdulhakem Alnahari ${ }^{1}$, Omar Hassan Alenezi ${ }^{1,5}$, Diala El Chbib ${ }^{6}$, Zahraa Yahya ${ }^{7}$, Eiman Ahmed ${ }^{8}$, Shoaib \\ Ahmad $^{9}$, Saad Uakkas ${ }^{10}$, Majdi Mohammed Sabahelzain ${ }^{11}$, Bushra Ahmed Alyamani ${ }^{1}$, Arash Nemat ${ }^{12}$, \\ Don Eliseo Lucero-Prisno III $^{13}$ \& Ashraf Zaghloul ${ }^{1}$ \\ ${ }^{1}$ Department of Health Administration and Behavioral Sciences, High Institute of Public Health, Alexandria \\ University, Alexandria, Egypt \\ ${ }^{2}$ Department of Public Health, Medical Research Office, Sudanese Medical Research Association, Khartoum, \\ Sudan \\ ${ }^{3}$ Faculty of Pharmacy, University of Ibadan, Ibadan, Nigeria \\ ${ }^{4}$ Department of Community Medicine, Faculty of Medicine, University of Tripoli, Libya \\ ${ }^{5}$ Public Health Administration, Kuwait Ministry of Health, Kuwait \\ ${ }^{6}$ Lebanese University, Faculty of Medical Sciences, Beirut, Lebanon \\ ${ }^{7}$ Department of Food Health and Nutrition, College of Food Science, Al-Qasim Green University, Babylon, Iraq \\ ${ }^{8}$ School of Global Public Health, New York University, New York, United States \\ ${ }^{9}$ Punjab Medical College, Faisalabad, Pakistan \\ ${ }^{10}$ Faculty of Medicine, University Mohammed, Rabat, Morocco \\ ${ }^{11}$ Department of Public Health, School of Health Sciences, Ahfad University for Women, Umdurman, Sudan \\ ${ }^{12}$ Department of Microbiology, Kabul University of Medical Sciences, Kabul, Afghanistan \\ ${ }^{13}$ Department of Global Health and Development, London School of Hygiene and Tropical Medicine, London, \\ United Kingdom
}

Correspondence: Yasir Ahmed Mohammed Elhadi, High Institute of Public Health, Alexandria University, 165 El Horreya Avenue 21561 Alexandria, Egypt.

Received: June 13, 2021 Accepted: July 8, 2021 Online Published: July 26, 2021

doi:10.5539/gjhs.v13n9p42 URL: https://doi.org/10.5539/gjhs.v13n9p42

\begin{abstract}
Background: Willingness of healthcare workers to be vaccinated is an important factor to be considered for a successful COVID-19 vaccination programme. This study aims to understand the willingness of health workers to receive a COVID-19 vaccine and its associated concerns across 10 countries in the Eastern Mediterranean Region (EMR).

Method: A cross-sectional study was conducted in January 2021 among healthcare workers in EMR using an online survey. Data were analyzed using IBM SPSS software package version 20.0.

Results: A total of 2806 health workers (physicians, nurses and pharmacists) completed and returned the informed consent along with the questionnaire electronically. More than half of the respondents $(58.0 \%)$ were willing to receive a COVID-19 vaccine, even if the vaccination is not mandatory for them. On the other hand, $25.7 \%$ of respondents were not willing to take COVID-19 vaccine while $16.3 \%$ were undecided. The top three reasons for not willing to be vaccinated were unreliability of COVID-19 vaccine clinical trials $(62.0 \%)$, fear of the side effects of the vaccine (45.3\%), and that COVID-19 vaccine will not give immunity for a long period of time $(23.1 \%)$.
\end{abstract}

Conclusion: Overall, the study revealed suboptimal acceptance of COVID-19 vaccine among the respondents in the EMR. Significant refusal of COVID-19 vaccine among healthcare professionals can reverse hard-won progress in building public trust in vaccination program. The findings suggest the need to develop tailored strategies to 
address concerns identified in the study in order to ensure optimal vaccine acceptance among healthcare workers in the EMR.

Keywords: COVID-19, vaccination, healthcare workers, global health, Eastern Mediterranean Region

\section{Introduction}

Coronavirus disease (COVID-19) is an infectious disease caused by the novel coronavirus that was first discovered in Wuhan, China. In 2020, the World Health Organization (WHO) declared the outbreak a global health emergency and later a pandemic after it has spread to many countries of the world (Cucinotta \& Vanelli, 2020). COVID-19 pandemic has raised immense global concerns for humanity and has posed unprecedented challenges to healthcare systems worldwide. As of 12 July 2021, globally, there have been 187,632,756 confirmed cases of COVID-19 reported to the WHO, including 4,049,071 deaths. Unsurprisingly, healthcare workers account for a number of the reported cases (Gagneux-Brunon et al., 2021).

The healthcare workers are on the first line of the battle against the COVID-19 (Nemat et al., 2020). Thus, protecting them should be one of the top priorities in the fight. Their contacts with patients can facilitate the spread of the virus (Jin et al., 2020). Moreso, healthcare workers are at highest risk of COVID-19 exposure and mortality due to work environment conditions, including personal protective equipment (PPE) shortages, insufficient staffing, and inadequate safety training and preparation amid the COVID-19 pandemic (Nemat et al., 2020). As of July 2020, the United Nations announced that over 1.4 million infections of COVID-19 are accounted for in healthcare workers, at least $10 \%$ of all cases. Comparisons of healthcare workers with and without COVID-19 infection showed an increased relative risk related to personal protective equipment, workplace setting, profession, exposure, contacts, and testing (Gholami et al., 2021).

In low-income countries, healthcare workers are more vulnerable to the devastating impact of COVID-19. Being away from home and facing the hardship of fighting COVID-19 place healthcare workers in dire situations (Nemat et al., 2020). The economic hardship is another major problem facing healthcare workers amid the pandemic (Kelley et al., 2020). The COVID-19 pandemic continues to pose multiple health challenges across the world. In the Eastern Mediterranean Region (EMR), morbidity and mortality from the disease remain serious causes for concern (Al-Mandhari, 2020). Concerns like these can pose serious psychological health impact on healthcare workers (Lai et al., 2020), hence causing serious health implications for them.

Since the emergence of the pandemic, the world is desperately waiting for a safe and effective vaccine. Efforts such as preventative measures have been put into action to curb the spread of the virus (Koirala et al., 2020). However, implementing a global vaccination program with broad range of clinical and socioeconomic benefits is the most effective means to end the pandemic (Adebisi et al., 2020). Starting in December 2020, several vaccines against COVID-19 have been authorized (Schaffer Deroo et al., 2020). However, with the growing vaccination coverage, under-vaccinated or non-vaccinated communities are still a concern for vaccination programs worldwide (Pugliese-Garcia et al., 2018).

The complex phenomenon of vaccine hesitancy refers to "delay in acceptance or refusal of vaccines despite availability of vaccine services" (Dubé et al., 2014), it is one of the top public health issues listed by the WHO (Graham, 2019). Despite of proven safety, efficacy and effectiveness of vaccines, an increasing number of individuals perceive vaccines as unsafe and unnecessary (Dubé et al., 2013). Addressing vaccine hesitancy among healthcare workers is crucial. Healthcare workers are considered one of the most important strata of society and a priority target group for COVID-19; vaccinating them is an utmost task for the world. However, willingness to take COVID-19 vaccine depends on the confidence and safety of the vaccine. Amid the pandemic, healthcare workers have also shown skepticism towards vaccines even in developed countries (Dror et al., 2020; Karafillakis et al., 2016). This is a point of great concern for the world since healthcare workers are the most credible and trusted sources of the information; and their doubt on vaccine will subjugate other people to follow the same belief pattern.

To find out the behaviour of healthcare workers towards vaccination in a bigger context, this study has been conceived. This research is aimed at understanding the willingness of healthcare workers (physicians, nurses, and pharmacists) from 10 countries in Eastern Mediterranean Region to receive COVID-19 vaccines.

\section{Method}

\subsection{Study Design and Sampling Technique}

This is a cross-sectional survey among health workers (physicians, nurses, and pharmacists) in 10 countries in the Eastern Mediterranean Region (Afghanistan, Egypt, Iraq, Kuwait, Lebanon, Libya, Morocco, Pakistan, Sudan, and Yemen). Non-probability convenient sampling technique was used to recruit the respondents. The inclusion 
criteria were being a physician, a nurse or a pharmacist working in one of the study countries at the time of data collection and having access to Internet connection to fill out the online questionnaire. Individuals who do not consent to participate in the study were excluded.

\subsection{Study Instrument and Administration}

A short online questionnaire was developed which was based on similar studies (Adebisi et al., 2020). It comprised sections on the demographic characteristics of the respondents including nationality, age, sex, marital status, profession and years of work experience which were all considered independent variables.

Outcome variables include the respondents' willingness to vaccinate against COVID-19 and the reasons for not willing to undertake COVID-19 vaccination among non-intenders. For example, question 1 was: if you are given the option to choose to take COVID-19 vaccine, will you take the vaccine? (With a Yes, No or Undecided options). Participants who answered not willing or undecided yet, were further asked question 2: what is your reason(s) for not willing to be vaccinated against COVID-19? The questionnaire was pilot-tested and comments were used to revise it.

The questions were entered into an online survey system and a link to the electronic questionnaire was generated. The final questionnaire was distributed by the research team members in each country to respondents across social media platforms, specifically groups of health workers as used in previous studies (Awucha et al., 2020). The data collection took place in January 2021.

\subsection{Data Analysis}

Data was analyzed using IBM SPSS software package version 20.0 (Armonk, NY: IBM Corp). The Kolmogorov-Smirnov was used to verify the normality of distribution of variables and comparisons between groups for categorical variables were assessed using Chi-square test. Binary logistic regression analysis was carried out to identify parameters more strongly associated with respondents' willingness to vaccinate against COVID-19. Significance of the obtained results was set at the $5 \%$ level of alpha error.

\subsection{Ethical Considerations}

This study has been approved by the Ethics and Technical Committee of High Institute of Public Health Alexandria University. Confidentiality and anonymity were also ensured by not putting names or attaching any identifiable codes to the online questionnaires. The rights of the participants to withdraw anytime from the study were also clearly stated in the online survey.

\section{Results}

\subsection{Sociodemographic and Professional characteristics of Respondents}

A total of 2,806 health workers with 1,413 females (50.4\%) and 1,393 males (49.6\%) from 10 countries in the EMR completed the online survey. The mean age of the participants was 31.3 ( \pm 9.1 years). Most respondents were physicians $(58.0 \%)$. Table 1 shows the sociodemographic characteristics of the respondents.

Table 1. Sociodemographic characteristics of study respondents

\begin{tabular}{lcc}
\hline Socio demographic data & Number & \% \\
\hline Nationality & & \\
Egypt & 261 & 9.3 \\
Sudan & 520 & 18.5 \\
Yemen & 717 & 25.6 \\
Libya & 328 & 11.7 \\
Kuwait & 239 & 8.5 \\
Iraq & 127 & 4.5 \\
Morocco & 111 & 4.0 \\
Afghanistan & 143 & 5.1 \\
Pakistan & 152 & 5.4 \\
Lebanon & 208 & 7.4 \\
\hline
\end{tabular}




\begin{tabular}{lcc}
\hline Sex & 1393 & 49.6 \\
Male & 1413 & 50.4 \\
Female & 1577 & 56.2 \\
\hline Age (years) & 1023 & 36.5 \\
$18-30$ & 174 & 6.2 \\
$31-45$ & 32 & 1.1 \\
$46-60$ & $31.3 \pm 9.1$ & \\
$61+$ & & 53.2 \\
Mean \pm SD. & 1494 & 43.0 \\
\hline Marital Status & 1206 & 3.8 \\
Single & 106 & \\
Married & & 58.0 \\
Divorced / widowed & 1628 & 25.8 \\
\hline Profession & 724 & 16.2 \\
Physician & 454 & 25.7 \\
Pharmacist & & 16.3 \\
Nurse & 722 & 57.9 \\
\hline Years of Working Experience & 458 & \\
Less than 2 years & 1626 & \\
2-5 years & & \\
More than 5 years & & \\
\hline & & \\
\hline
\end{tabular}

\subsection{Health Workers' Willingness to be Vaccinated}

More than half of the respondents (58.0\%) were willing to receive COVID-19 vaccine, even if the vaccination is not mandatory for them. On the other hand, $25.7 \%$ of respondents were not willing to vaccinate against COVID-19 while $16.3 \%$ answered 'undecided'. Figure 1 shows willingness to vaccinate against COVID-19 among health professionals in studied countries.

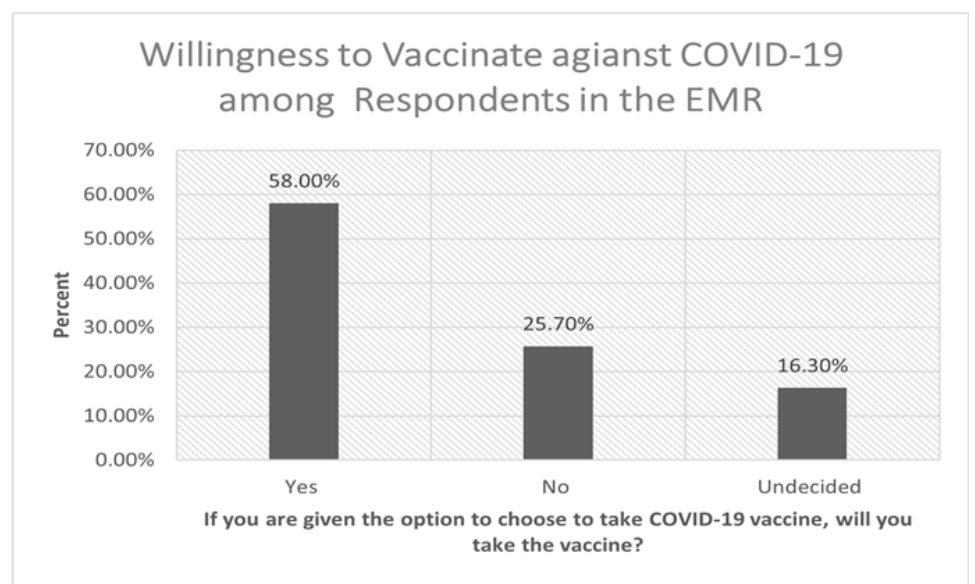

Figure 1. Willingness to be vaccinated against COVID-19 among health professionals in EMR countries

\subsection{Variables Associated with Respondents' Willingness to Receive COVID-19 Vaccines}

As shown on Table 2, results indicated respondent's nationality (P value $<0.001$ ), sex (P value $<0.001$ ), marital 
status ( $\mathrm{P}$ value $<0.022$ ), profession ( $\mathrm{P}$ value $<0.001$ ) and years of working experience were significantly associated with willingness to receive COVID-19 vaccination. However, there was no significant association between age group and willingness to receive COVID-19 vaccine. Additionally, Figure 2 below shows high vaccine acceptance among healthcare professionals working in Afghanistan (72.0\%) and Libya (70.0\%).

Table 2. Association between sociodemographic variables and respondents' willingness to receive COVID-19 vaccine

\begin{tabular}{|c|c|c|c|c|}
\hline \multirow{2}{*}{$\begin{array}{l}\text { Sociodemographic } \\
\text { variables }\end{array}$} & \multicolumn{2}{|c|}{$\begin{array}{l}\text { If you are given the option to choose to take COVID-19 vaccine, } \\
\text { will you take the vaccine? }\end{array}$} & \multicolumn{2}{|c|}{ Test of Significance } \\
\hline & Yes $(n=1626)$ & No/Undecided $(\mathrm{n}=1180)$ & $\chi^{2}$ & $\mathbf{p}$ \\
\hline \multicolumn{5}{|l|}{ Nationality } \\
\hline Egypt & $119(7.3 \%)$ & $142(12.0 \%)$ & \multirow{10}{*}{$122.43^{*}$} & \multirow{10}{*}{$<0.001^{*}$} \\
\hline Sudan & $292(18.0 \%)$ & $228(19.3 \%)$ & & \\
\hline Yemen & $464(28.5 \%)$ & $253(21.4 \%)$ & & \\
\hline Libya & $230(14.1 \%)$ & $98(8.3 \%)$ & & \\
\hline Kuwait & $103(6.3 \%)$ & $136(11.5 \%)$ & & \\
\hline Iraq & $58(3.6 \%)$ & $69(5.8 \%)$ & & \\
\hline Morocco & $64(3.9 \%)$ & $47(4.0 \%)$ & & \\
\hline Afghanistan & $103(6.3 \%)$ & $40(3.4 \%)$ & & \\
\hline Pakistan & $106(6.5 \%)$ & $46(3.9 \%)$ & & \\
\hline Lebanon & $87(5.4 \%)$ & $121(10.3 \%)$ & & \\
\hline \multicolumn{5}{|l|}{ Sex } \\
\hline Male & $926(56.9 \%)$ & $467(39.6 \%)$ & \multirow{2}{*}{$82.55^{*}$} & \multirow{2}{*}{$<0.001^{*}$} \\
\hline Female & $700(43.1 \%)$ & $713(60.4 \%)$ & & \\
\hline \multicolumn{5}{|l|}{ Age (years) } \\
\hline $18-30$ & $904(55.6 \%)$ & $673(57 \%)$ & \multirow{4}{*}{1.766} & \multirow{4}{*}{0.622} \\
\hline $31-45$ & $608(37.4 \%)$ & $415(35.2 \%)$ & & \\
\hline $46-60$ & $96(5.9 \%)$ & $78(6.6 \%)$ & & \\
\hline $61+$ & $18(1.1 \%)$ & $14(1.2 \%)$ & & \\
\hline \multicolumn{5}{|l|}{ Marital Status } \\
\hline Single & $865(53.2 \%)$ & $629(53.3 \%)$ & \multirow{3}{*}{$7.66^{*}$} & \multirow{3}{*}{$0.022 *$} \\
\hline Married & $713(43.8 \%)$ & $493(41.8 \%)$ & & \\
\hline Divorced / widowed & $48(3 \%)$ & $58(4.9 \%)$ & & \\
\hline \multicolumn{5}{|l|}{ Profession } \\
\hline Physicians & $993(61.1 \%)$ & $635(53.8 \%)$ & \multirow{3}{*}{$20.69 *$} & \multirow{3}{*}{$<0.001 *$} \\
\hline Pharmacists & $369(22.7 \%)$ & $355(30.1 \%)$ & & \\
\hline Nurses & $264(16.2 \%)$ & $190(16.1 \%)$ & & \\
\hline \multicolumn{5}{|l|}{ Experience (Years) } \\
\hline Less than 2 years & $0(0 \%)$ & $722(61.2 \%)$ & \multirow{3}{*}{$2806.0^{*}$} & \multirow{3}{*}{$<0.001^{*}$} \\
\hline $2-5$ years & $0(0 \%)$ & $458(38.8 \%)$ & & \\
\hline More than 5 years & $1626(100 \%)$ & $0(0 \%)$ & & \\
\hline
\end{tabular}

$\chi^{2}$ : Chi square test.

*: Statistically significant at $\mathrm{p} \leq 0.05$. 


\subsection{Parameters Affecting Health Workers' Willingness to Receive COVID-19 Vaccines}

As shown on Table 3, Health professionals working in Sudan ( $\mathrm{P}<0.001)$, Yemen $(\mathrm{P}<0.001)$, Libya $(\mathrm{P}<0.001)$; Afghanistan ( $\mathrm{P}<0.001)$, Pakistan $(\mathrm{P}<0.001)$ or Morocco $(\mathrm{P}<0.001)$ were more likely to be willing to receive COVID-19 vaccine than healthcare professionals working in the other countries. Females $(\mathrm{P}<0.001)$, pharmacists $(\mathrm{P}<0.001)$ and older ages $(\mathrm{P}<0.001)$ were more significantly associated with having reservations towards vaccination (not willing or have not decided to receive COVID-19 vaccine).

Table 3. Multivariate binary logistic regression analysis for the parameters affecting health workers' willingness to receive COVID-19 vaccines

\begin{tabular}{lllll}
\hline Variables & $\mathbf{p}$ & OR & $\mathbf{9 5 \%}$ C.I & \\
\cline { 5 - 5 } & & & UL & LL \\
\hline Nationality & & & & \\
Egypt & 0.308 & 0.820 & 0.560 & 1.201 \\
Sudan & $<0.001^{*}$ & 0.541 & 0.388 & 0.754 \\
Yemen & $<0.001^{*}$ & 0.408 & 0.293 & 0.568 \\
Libya & $<0.001^{*}$ & 0.305 & 0.208 & 0.449 \\
Kuwait & 0.965 & 0.991 & 0.666 & 1.474 \\
Iraq & 0.967 & 0.991 & 0.628 & 1.563 \\
Morocco & $0.019^{*}$ & 0.566 & 0.352 & 0.912 \\
Afghanistan & $<0.001^{*}$ & 0.364 & 0.227 & 0.584 \\
Pakistan & $<0.001^{*}$ & 0.397 & 0.251 & 0.628 \\
Lebanon & 0.308 & 0.820 & 0.560 & 1.201 \\
\hline Age (Years) & $0.031^{*}$ & 1.013 & 1.001 & 1.024 \\
\hline Sex (Female) & $<0.001^{*}$ & 1.898 & 1.610 & 2.238 \\
\hline Marital Status & & & & \\
Single ${ }^{*}$ & & & 1.281 & 1.039 \\
Married & 1.039 & 0.843 & 2.283 & 1.473 \\
Divorced / widowed & 1.473 & 0.950 & & \\
\hline Profession & & & 0.751 & 1.195 \\
Physician ${ }^{*}$ & & & &
\end{tabular}

OR: Odds ratio.

CI: Confidence interval.

LL: Lower limit.

UL: Upper Limit.

(B: reference group.

*: Statistically significant at $\mathrm{p} \leq 0.05$.

\subsection{Vaccination Hesitancy among Health Workers in the Studied EMR Countries}

In this study, vaccine hesitancy is described as unwillingness to take COVID-19 vaccine despite the availability, confirmed safety and efficacy. Figure 2 shows the COVID-19 vaccine acceptance, and hesitancy level among health care workers by countries, with the highest vaccine hesitancy observed in Lebanon (58.2\%), Kuwait (56.9\%) and Egypt (54.4\%). 


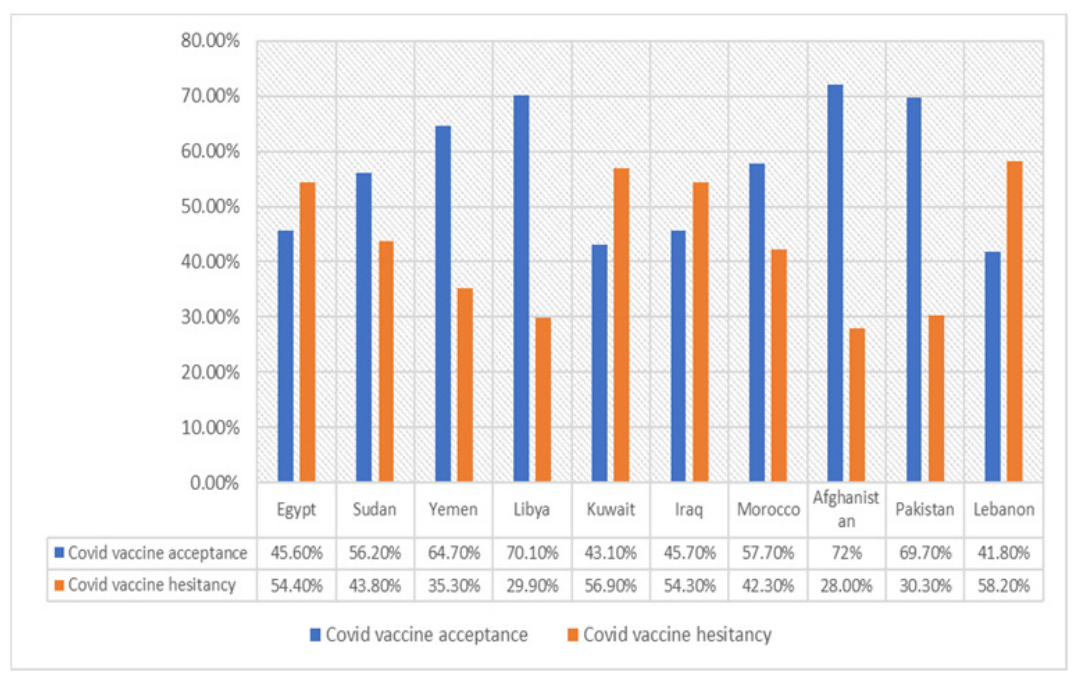

Figure 2. COVID-19 vaccine acceptance and hesitancy among health workers by countries

\subsection{Reasons Associated with COVID-19 Vaccination Hesitancy}

Table 4 shows various reasons associated with COVID-19 vaccine hesitancy among the respondents. The unreliability of COVID-19 vaccine clinical trials and fear of the vaccine side effects were reported as reasons behind COVID-19 vaccine hesitancy at $62.0 \%$ and $45.0 \%$ of the study participants, respectively. Approximately $23.0 \%$ of the healthcare professionals thought that the vaccine would not give immunity for an extended period.

Table 4. Respondents' reported concerns towards COVID-19 vaccination

\begin{tabular}{lll}
\hline Reported concerns & Number & \% \\
\hline Unreliability of COVID-19 vaccine clinical trials & 736 & 62.0 \\
Fear of the side effects of the vaccine & 535 & 45.3 \\
COVID-19 vaccine will not give immunity for a long period & 272 & 23.1 \\
The immune system is sufficient to defeat the virus & 216 & 18.3 \\
COVID-19 vaccine is likely to be expensive & 123 & 10.4 \\
Strict infection control measures in my health facility (s) are sufficient to protect from the virus & 99 & 8.4 \\
The vaccine is not necessary since the mortality rate is very low & 80 & 6.8 \\
Results of safety and efficiency are still not completed & 63 & 5.3 \\
Adverse events should be observed at the developed countries for some time & 57 & 4.8 \\
After a lot of people take the vaccine and I see them safe I could take it & 49 & 4.6 \\
Symptomatic treatment is sufficient & 23 & 11 \\
Personal protective equipment and hygiene is enough & 37 & 0.9 \\
The vaccine can cause death & 3.1 \\
\hline
\end{tabular}

\section{Discussion}

Vaccination is an important public health tool and one of the most important advances in healthcare in the fight against infectious diseases (Alaran et al., 2021). It is responsible for the eradication of rinderpest and smallpox and the control of infectious diseases such as polio in many parts of the world (Adebisi et al., 2020). It is therefore clear that a safe, highly effective, and globally acceptable and equitable vaccination program, together with pre-existing precautionary measures, is essential to effectively contain the outbreak (Lucero-Prisno et al., 2021).

It is often mistakenly believed that healthcare professionals attitudes must be positive towards vaccines because they have scientific and medical training. However, this is not always the case because healthcare workers are not 
a homogenous group, and most are not experts in the field of vaccination. This study presents insights into the willingness of healthcare professionals in the EMR region. Healthcare workers are among the priority groups to receive vaccination, thus it is important to understand their attitude towards and willingness to take COVID-19 vaccine (Shekhar et al., 2021). This understanding will provide better insights to address barriers to widespread COVID-19 vaccination acceptance.

Interestingly, it was found that overall, more than half (58.0\%) of the study respondents are willing to take the COVID-19 vaccine. The study also revealed that less than half of the respondents in Egypt, Kuwait, Iraq, and Lebanon are willing to take the COVID-19 vaccine. Similarly, a study also revealed that $28 \%$ of healthcare workers in Democratic Republic of Congo are willing to take the COVID-19 vaccine (Ditekemena et al., 2021). A study among healthcare workers in the United States revealed that only one in three said they would take the vaccine immediately when it becomes available (Shekhar et al., 2021). In Malta, only half of the participants (healthcare workers) stated that they intend to take the COVID-19 vaccine (Grech et al., 2020). Less than half of the healthcare workers in a survey conducted in France and in the French-speaking part of Belgium and Canada showed high acceptance of COVID-19 vaccine (Verger et al., 2021). Some of these findings are worrisome because healthcare professionals are expected to have a considerable understanding of the safety and efficacy as well as the benefits COVID-19 vaccine can reap for the pandemic response.

In addition, healthcare workers, as models, are typically entrusted with the task of providing reliable information about health issues to the public and this is associated with greater compliance with health interventions. The study revealed high vaccine acceptance among healthcare professionals working in Afghanistan (72.0\%) and Libya $(70.0 \%)$. This can be compared to a study in Turkey, where $68.8 \%$ of the healthcare worker are willing to take the COVID-19 vaccine (Kose et al., 2021).

Findings from this study also revealed that the three major reasons for not willing to be vaccinated are "unreliability of COVID-19 vaccine clinical trials", "fear of the side effects of the vaccine", and "COVID-19 vaccine will not give immunity for a long period." This presents a challenge because healthcare professionals provide a key role in influencing the behavior and acceptance of vaccines by their patients. They serve as an important source of information for the general public and during patient consult, they can be a key factor in the decision of the patient to be vaccinated or not. There is a significant need to address concerns and increase awareness to improve chances for higher acceptance of a COVID-19 vaccine. Otherwise, this poses additional possibility of mass rejection of COVID-19 vaccine in the general population.

A major strength of the study is the large sample size thus providing a better picture of the population studied. The survey population is also diverse with representation from different gender groups, ages, ethnicities, and roles in healthcare. However, the study is not without limitations. There is a risk of selection bias, and this would limit the generalizability of the study findings to all the healthcare professionals in the EMR. The study only included nurses, physicians, and pharmacists. Despite these limitations, these findings are not inconsistent with the findings from other studies about the willingness to be vaccinated or vaccine hesitancy among healthcare workers. The survey questionnaire was available in English and distributed in an online format, which may have introduced selection bias favoring English-literate HCWs and those with access to the Internet. Social desirability bias may also affect the interpretation of the study results. Moreover, the survey was conducted in January 2021 when information regarding COVID-19 vaccines may have not circulated widely. Therefore, it possible that intention to be vaccinated would have changed.

\section{Conclusion}

Overall, this study revealed suboptimal acceptance of COVID-19 vaccine among the respondents in the EMR region. The study elucidated the landscape and a number of factors with regards to vaccine hesitancy and acceptance. Significant refusal of COVID-19 vaccine among healthcare professionals can reverse hard-won progress in building public trust in COVID-19 vaccination program. Study findings suggest the need to develop tailor-made strategies to address concerns identified in the study in order to ensure optimal vaccine acceptance among healthcare workers in the EMR. The study also provides a glimpse on how the health community will move forward in this area which will immensely contribute to the initiatives against the pandemic.

\section{Acknowledgments}

We would like to thank Mohammed Yasir Essar for his assistance in conducting the study.

\section{Funding}

The author(s) received no specific funding for this work. 


\section{Informed Consent Statement}

Informed consent was obtained from all subjects involved in the study.

\section{Data Availability Statement}

The data presented in this study are available on request from the corresponding author.

\section{Competing Interests Statement}

The authors declare that there are no competing or potential conflicts of interest.

\section{Authors' Contributions}

The concept for this study was developed by Y. A. M. E., and he wrote the first draft. Y. A. M. E., H. M. E., S. A. A., O. H. A., D. E. C., Z. Y., E. A., S. A., S. U., B. A. A. and A. N. collected the data and developed the draft with an important contribuation from A. M., Y. A. A., M. M. S., D. E. L and A. Z. in writing, reviewing and editing.

\section{References}

Adebisi, Y. A., Alaran, A. J., Bolarinwa, O. A., Akande-Sholabi, W., \& Lucero-Prisno, D. E. (2020). When it is available, will we take it? Public perception of hypothetical COVID-19 vaccine in Nigeria. In medRxiv (p. 2020.09.24.20200436). medRxiv. https://doi.org/10.1101/2020.09.24.20200436

Adebisi, Y. A., Eliseo-Lucero Prisno, D., \& Nuga, B. B. (2020). Last fight of wild polio in Africa: Nigeria's battle. Public Health in Practice, 1, 100043. https://doi.org/10.1016/j.puhip.2020.100043

Al-Mandhari, A. (2020). Coming together in the region to tackle COVID-19. In Eastern Mediterranean Health Journal (Vol. 26, Issue 9, pp. 992-993). World Health Organization. https://doi.org/10.26719/2020.26.9.992

Alaran, A. J., Adebisi, Y. A., Badmos, A., Khalid-Salako, F., Gaya, S. K., Ilesanmi, E. B., ... \& Lucero-Prisno, D. E. (2021). Uneven power dynamics must be levelled in COVID-19 vaccines access and distribution. Public Health in Practice, 2, 100096. https://doi.org/10.1016/j.puhip.2021.100096

Awucha, N. E., Janefrances, O. C., Meshach, A. C., Henrietta, J. C., Daniel, A. I., \& Chidiebere, N. E. (2020). Impact of the COVID-19 pandemic on consumers' access to essential medicines in Nigeria. American Journal of Tropical Medicine and Hygiene, 103(4), 1630-1634. https://doi.org/10.4269/ajtmh.20-0838

Cucinotta, D., \& Vanelli, M. (2020). WHO declares COVID-19 a pandemic. In Acta Biomedica (Vol. 91, Issue 1, pp. 157-160). Mattioli 1885. https://doi.org/10.23750/abm.v91i1.9397

Ditekemena, J. D., Nkamba, D. M., Mutwadi, A., Mavoko, H. M., Siewe Fodjo, J. N., Luhata, C., Obimpeh, M., Van Hees, S., Nachega, J. B., \& Colebunders, R. (2021). COVID-19 Vaccine Acceptance in the Democratic Republic of Congo: A Cross-Sectional Survey. Vaccines, 9(2), 153. https://doi.org/10.3390/vaccines9020153

Dror, A. A., Eisenbach, N., Taiber, S., Morozov, N. G., Mizrachi, M., Zigron, A., ... \& Sela, E. (2020). Vaccine hesitancy: the next challenge in the fight against COVID-19. European Journal of Epidemiology, 35(8), 775-779. https://doi.org/10.1007/s10654-020-00671-y

Dubé, E., Gagnon, D., Nickels, E., Jeram, S., \& Schuster, M. (2014). Mapping vaccine hesitancy-Country-specific characteristics of a global phenomenon. Vaccine, 32(49), 6649-6654. https://doi.org/10.1016/j.vaccine.2014.09.039

Dubé, E., Laberge, C., Guay, M., Bramadat, P., Roy, R., \& Bettinger, J. (2013). Vaccine hesitancy: An overview. In Human Vaccines and Immunotherapeutics (Vol. 9, Issue 8, pp. 1763-1773). Taylor \& Francis. https://doi.org/10.4161/hv.24657

Elhadi, Y. A. M., Adebisi, Y. A., Hassan, K. F., Mohammed, S. E. E., Lin, X., \& Lucero-Prisno III, D. E. (2020). The formidable task of fighting COVID-19 in Sudan. Pan African Medical Journal, 35. https://doi.org/10.11604/pamj.supp.2020.35.2.24984

Gagneux-Brunon, A., Detoc, M., Bruel, S., Tardy, B., Rozaire, O., Frappe, P., \& Botelho-Nevers, E. (2021). Intention to get vaccinations against COVID-19 in French healthcare workers during the first pandemic wave: a cross-sectional survey. Journal of Hospital Infection, 108, 168-173. https://doi.org/10.1016/j.jhin.2020.11.020

Gholami, M., Fawad, I., Shadan, S., Rowaiee, R., Ghanem, H. A., Hassan Khamis, A., \& Ho, S. B. (2021). COVID-19 and healthcare workers: A systematic review and meta-analysis. International Journal of Infectious Diseases, 104, 335-346. https://doi.org/10.1016/j.ijid.2021.01.013

Graham, F. (2019). Daily briefing: WHO calls out 'vaccine hesitancy' as top 10 health threat. Nature. 
https://doi.org/10.1038/d41586-019-00188-9

Grech, V., Gauci, C., \& Agius, S. (2020). Vaccine hesitancy among Maltese healthcare workers toward influenza and novel COVID-19 vaccination. Early Human Development, 105213. https://doi.org/10.1016/j.earlhumdev.2020.105213

Jin, Y. H., Huang, Q., Wang, Y. Y., Zeng, X. T., Luo, L. S., Pan, Z. Y., ... \& Wang, X. H. (2020). Perceived infection transmission routes, infection control practices, psychosocial changes, and management of COVID-19 infected healthcare workers in a tertiary acute care hospital in Wuhan: A cross-sectional survey. Military Medical Research, 7(1), 24. https://doi.org/10.1186/s40779-020-00254-8

Karafillakis, E., Dinca, I., Apfel, F., Cecconi, S., Würz, A., Takacs, J., Suk, J., Celentano, L. P., Kramarz, P., \& Larson, H. J. (2016). Vaccine hesitancy among healthcare workers in Europe: A qualitative study. Vaccine, 34(41), 5013-5020. https://doi.org/10.1016/j.vaccine.2016.08.029

Kelley, M., Ferrand, R. A., Muraya, K., Chigudu, S., Molyneux, S., Pai, M., \& Barasa, E. (2020). An appeal for practical social justice in the COVID-19 global response in low-income and middle-income countries. In The Lancet Global Health (Vol. 8, Issue 7, pp. e888-e889). Elsevier Ltd. https://doi.org/10.1016/S2214-109X(20)30249-7

Koirala, A., Joo, Y. J., Khatami, A., Chiu, C., \& Britton, P. N. (2020). Vaccines for COVID-19: The current state of play. In Paediatric Respiratory Reviews (Vol. 35, pp. 43-49). W.B. Saunders Ltd. https://doi.org/10.1016/j.prrv.2020.06.010

Kose, S., Mandiracioglu, A., Sahin, S., Kaynar, T., Karbus, O., \& Ozbel, Y. (2021). Vaccine hesitancy of the COVID-19 by health care personnel. International Journal of Clinical Practice, 75(5), e13917. https://doi.org/10.1111/ijcp.13917

Lai, J., Ma, S., Wang, Y., Cai, Z., Hu, J., Wei, N., ... \& Hu, S. (2020). Factors Associated With Mental Health Outcomes Among Health Care Workers Exposed to Coronavirus Disease 2019. JAMA Network Open, 3(3), e203976. https://doi.org/10.1001/jamanetworkopen.2020.3976

Lucero-Prisno, D. E., Ogunkola, I. O., Imo, U. F., \& Adebisi, Y. A. (2021). Perspective piece who will pay for the COVID-19 vaccines for Africa? In American Journal of Tropical Medicine and Hygiene (Vol. 104, Issue 3, pp. 794-796). American Society of Tropical Medicine and Hygiene. https://doi.org/10.4269/ajtmh.20-1506

Nemat, A., Asady, A., Raufi, N., Zaki, N., Ehsan, E., Noor, N. A. S., \& Zeng, Q. (2020). A Survey of the Healthcare Workers in Afghanistan during the COVID-19 Pandemic. The American Journal of Tropical Medicine and Hygiene, 104(2), 537-539. https://doi.org/10.4269/ajtmh.20-1367

Pugliese-Garcia, M., Heyerdahl, L. W., Mwamba, C., Nkwemu, S., Chilengi, R., Demolis, R., Guillermet, E., \& Sharma, A. (2018). Factors influencing vaccine acceptance and hesitancy in three informal settlements in Lusaka, Zambia. Vaccine, 36(37), 5617-5624. https://doi.org/10.1016/j.vaccine.2018.07.042

Schaffer Deroo, S., Pudalov, N. J., \& Fu, L. Y. (2020). Planning for a COVID-19 Vaccination Program. In JAMA Journal of the American Medical Association (Vol. 323, Issue 24, pp. 2458-2459). American Medical Association. https://doi.org/10.1001/jama.2020.8711

Shekhar, R., Sheikh, A. B., Upadhyay, S., Singh, M., Kottewar, S., Mir, H., Barrett, E., \& Pal, S. (2021). COVID-19 Vaccine Acceptance among Health Care Workers in the United States. Vaccines, 9(2), 119. https://doi.org/10.3390/vaccines9020119

Verger, P., Scronias, D., Dauby, N., Adedzi, K. A., Gobert, C., Bergeat, M., Gagneur, A., \& Dubé, E. (2021). Attitudes of healthcare workers towards COVID-19 vaccination: a survey in France and French-speaking parts of Belgium and Canada, 2020. Eurosurveillance, 26(3), 2002047. https://doi.org/10.2807/1560-7917.ES.2021.26.3.2002047

\section{Copyrights}

Copyright for this article is retained by the author(s), with first publication rights granted to the journal.

This is an open-access article distributed under the terms and conditions of the Creative Commons Attribution license (http://creativecommons.org/licenses/by/4.0/). 